\title{
$n$-3 Fatty acids and rosiglitazone improve insulin sensitivity through additive stimulatory effects on muscle glycogen synthesis in mice fed a high-fat diet
}

\author{
O. Kuda • T. Jelenik • Z. Jilkova • P. Flachs • M. Rossmeisl • M. Hensler • L. Kazdova • \\ N. Ogston • M. Baranowski • J. Gorski • P. Janovska • V. Kus • J. Polak • \\ V. Mohamed-Ali • R. Burcelin • S. Cinti • M. Bryhn • J. Kopecky
}

Received: 12 December 2008 / Accepted: 2 February 2009 /Published online: 11 March 2009

(C) Springer-Verlag 2009

\begin{abstract}
Aims/hypothesis Fatty acids of marine origin, i.e. docosahexaenoic acid (DHA) and eicosapentaenoic acid (EPA) act as hypolipidaemics, but they do not improve glycaemic control in obese and diabetic patients. Thiazolidinediones like rosiglitazone are specific activators of peroxisome proliferator-activated receptor $\gamma$, which improve wholebody insulin sensitivity. We hypothesised that a combined treatment with a DHA and EPA concentrate (DHA/EPA) and rosiglitazone would correct, by complementary additive mechanisms, impairments of lipid and glucose homeostasis in obesity.
\end{abstract}

O. Kuda and T. Jelenik contributed equally to this work.

Electronic supplementary material The online version of this article (doi:10.1007/s00125-009-1305-z) contains supplementary material, which is available to authorised users.

O. Kuda $\cdot$ T. Jelenik $\cdot$ Z. Jilkova $\cdot$ P. Flachs $\cdot$ M. Rossmeisl $\cdot$

M. Hensler $\cdot$ P. Janovska $\cdot$ V. Kus $\cdot$ J. Kopecky $(\bowtie)$

Department of Adipose Tissue Biology,

Institute of Physiology of the Academy

of Sciences of the Czech Republic, v.v.i.,

Videnska 1083,

14220 Prague, Czech Republic

e-mail: kopecky@biomed.cas.cz

L. Kazdova

Institute of Clinical and Experimental Medicine,

Prague, Czech Republic

N. Ogston $\cdot$ V. Mohamed-Ali

Adipokines and Metabolism Research Group,

Centre for Clinical Pharmacology, Department of Medicine,

University College London,

London, UK
Methods Male C57BL/6 mice were fed a corn oil-based high-fat diet. The effects of DHA/EPA (replacing 15\% dietary lipids), rosiglitazone $(10 \mathrm{mg} / \mathrm{kg}$ diet $)$ or a combination of both on body weight, adiposity, metabolic markers and adiponectin in plasma, as well as on liver and muscle gene expression and metabolism were analysed. Euglycaemic-hyperinsulinaemic clamps were used to characterise the changes in insulin sensitivity. The effects of the treatments were also analysed in dietary obese mice with impaired glucose tolerance (IGT).

Results DHA/EPA and rosiglitazone exerted additive effects in prevention of obesity, adipocyte hypertrophy,

M. Baranowski $\cdot$ J. Gorski

Department of Physiology, Medical University of Bialystok, Bialystok, Poland

J. Polak

Department of Sport Medicine, 3rd Faculty of Medicine,

Charles University,

Prague, Czech Republic

R. Burcelin

INSERM U858 Institute of Molecular Medicine,

IFR31, Rangueil Hospital,

Toulouse, France

S. Cinti

Institute of Normal Human Morphology, University of Ancona,

Ancona, Italy

M. Bryhn

Silentia AS,

Svelvik, Norway 
low-grade adipose tissue inflammation, dyslipidaemia and insulin resistance, while inducing adiponectin, suppressing hepatic lipogenesis and decreasing muscle ceramide concentration. The improvement in glucose tolerance reflected a synergistic stimulatory effect of the combined treatment on muscle glycogen synthesis and its sensitivity to insulin. The combination treatment also reversed dietary obesity, dyslipidaemia and IGT.

Conclusions/interpretation DHA/EPA and rosiglitazone can be used as complementary therapies to counteract dyslipidaemia and insulin resistance. The combination treatment may reduce dose requirements and hence the incidence of adverse side effects of thiazolidinedione therapy.

Keywords Adiponectin - Diabetes · Docosahexaenoic acid · Eicosapentaenoic acid · Fish oil · Obesity · PPAR .

Rosiglitazone $\cdot$ Thiazolidinedione

\begin{tabular}{|c|c|}
\hline \multicolumn{2}{|l|}{ Abbreviations } \\
\hline $\mathrm{Akt} / \mathrm{PKB}$ & Protein kinase $\mathrm{B}$ \\
\hline $\mathrm{cHF}$ & Corn oil-based high-fat diet \\
\hline $\mathrm{cHF}+\mathrm{F}$ & $\begin{array}{l}\text { cHF diet supplemented with } \\
\text { eicosapentaenoic and } \\
\text { docosahexaenoic acids }\end{array}$ \\
\hline $\mathrm{cHF}+\mathrm{F}+\mathrm{TZD}$ & $\begin{array}{l}\text { cHF diet supplemented with } \\
\text { eicosapentaenoic and } \\
\text { docosahexaenoic acids and } \\
\text { rosiglitazone }\end{array}$ \\
\hline $\mathrm{cHF}+\mathrm{TZD}$ & cHF diet supplemented with rosiglitazone \\
\hline DHA & Docosahexaenoic acid \\
\hline EPA & Eicosapentaenoic acid \\
\hline HMW & High molecular weight \\
\hline IGT & Impaired glucose tolerance \\
\hline$n-3$ LC-PUFA & $\begin{array}{l}n-3 \text { Long-chain polyunsaturated } \\
\text { fatty acids }\end{array}$ \\
\hline PPAR & $\begin{array}{l}\text { Peroxisome proliferator-activated } \\
\text { receptor }\end{array}$ \\
\hline TZD & Thiazolidinedione \\
\hline
\end{tabular}

\section{Introduction}

Both dietary and pharmacological interventions are required for therapy of type 2 diabetic patients. Naturally occurring $n-3$ long-chain polyunsaturated fatty acids (LC-PUFA), namely eicosapentaenoic acid (EPA; 20:5 n-3) and docosahexaenoic acid (DHA; 22:6 n-3), which are abundant in sea fish, act as hypolipidaemics, reduce cardiac events and decrease progression of atherosclerosis, as reviewed by Ruxton et al. [1]. Therefore, $n-3$ LC-PUFA are now regarded as healthy constituents of diets for diabetic patients [2, 3]. Several studies in obese humans even demonstrated reductions of adiposity after $n$-3 LC-PUFA supplementation [4, 5]. However, $n$-3 LCPUFA appear to have little effect on glycaemic control in diabetic patients $[4,6,7]$. In rodents fed a high-fat diet, $n-3$ LC-PUFA efficiently prevented development of obesity [8-10] and of impaired glucose tolerance (IGT) $[11,12]$.

The effects of $n-3$ LC-PUFA are largely mediated by peroxisome proliferator-activated receptors (PPAR), with PPAR $-\alpha$ and PPAR $-\delta(-\beta)$ representing the main targets [13]. However, PPAR- $\gamma$, liver $\mathrm{X}$ receptor- $\alpha$, hepatic nuclear factor-4 and sterol regulatory element binding protein-1 are also involved [12, 14, 15]. Besides acting directly as regulatory ligands, $n-3$ LC-PUFA also act through their active metabolites, eicosanoids and other lipid molecules [16]. The hypolipidaemic and anti-obesity effects of $n$-3 LC-PUFA probably depend on the in situ suppression of lipogenesis and increase of fatty acid oxidation in several tissues [10, 14, 17]. This metabolic switch might reduce accumulation of toxic fatty acidderivatives, while protecting insulin signalling in liver and muscle $[11,12,18]$.

On the other hand, PPAR- $\gamma$ ligands [19] such as thiazolidinediones (TZDs) are the preferred therapeutic agents for insulin resistance in type 2 diabetic patients. However, TZDs like rosiglitazone and pioglitazone are also associated with unwanted side effects, such as oedema and weight gain [20], possible risk of heart failure [21] and bone loss [22]. These compounds are likely to improve glycaemic control mostly by repartitioning fat away from skeletal muscle [23], while augmenting insulin action in various tissues [24-29].

In spite of the differences in the ability of TZDs and $n-3$ LC-PUFA to reverse IGT, both types of compounds reduce adipose tissue inflammation [24, 30], one of the key factors contributing to the development of insulin resistance in obesity, while also increasing adiponectin $[12,15,24,25$, 31, 32].

We hypothesised that partially overlapping mechanisms of action of $n-3$ LC-PUFA and TZDs, namely the activation of metabolic switch by $n-3$ LC-PUFA and the induction of lipid repartitioning by TZDs, could have synergistic effects in a combination treatment, leading to an improvement of glycaemic profile so far not described for these strategies when considered separately. We therefore evaluated the effects of: (1) partial replacement of dietary lipids by $n$-3 LC-PUFA; (2) a low non obesogenic dose of rosiglitazone; and (3) a combination of both on whole-body parameters of glucose and lipid metabolism in mice fed high-fat diet. To further elucidate the effects of the treatments, a detailed analysis of liver and muscle metabolism was also performed. 


\section{Methods}

Animals and treatments Male mice were maintained (two animals per cage) at $22^{\circ} \mathrm{C}$ on a $12 \mathrm{~h}$ light-dark cycle (light on from 06:00 hours) and allowed free access to standard laboratory chow (lipid content $\sim 3.4 \% \mathrm{wt} / \mathrm{wt}$; extruded R/M$\mathrm{H}$ diet; Ssniff Spezialdiäten, Soest, Germany). Two types of studies were used.

First, a 'prevention study' was performed to characterise the effects of $n$-3 LC-PUFA, rosiglitazone and their combination, on developing obesity and IGT in mice fed high-fat diet. At 3 months of age, male C57BL/6N mice (Charles River Laboratories, Sulzfeld, Germany) were randomly assigned to a corn oil-based high-fat diet (cHF; lipid content $\sim 35.2 \% \mathrm{wt} / \mathrm{wt}$, mainly corn oil) or to the following treatments: (1) cHF diet supplemented with EPA and DHA $(\mathrm{cHF}+\mathrm{F})$ as concentrate of $n-3$ LC-PUFA (46\% DHA, $14 \%$ EPA; 1050TG; EPAX, Lysaker, Norway) replacing $15 \%$ of dietary lipids; (2) cHF diet supplemented with rosiglitazone (cHF+TZD) $(10 \mathrm{mg} / \mathrm{kg}$ diet $)$; and (3) cHF diet supplemented with EPA, DHA and rosiglitazone $(\mathrm{cHF}+\mathrm{F}+\mathrm{TZD})$ (see Electronic supplementary material [ESM] Tables 1 and 2). Some mice were maintained on the standard chow diet. Various analyses (described below) were performed at 5 to 20 weeks after initiation of treatment. Mice were killed under anaesthesia (09:00-11:00 hours) by cervical dislocation in ad libitum fed state, unless stated otherwise.

Second, in a 'reversal study', obesity and IGT were induced by feeding male C57BL/6J mice (The Jackson Laboratory, Bar Harbor, ME, USA) the cHF diet between 3 and 7 months of age, prior to the subsequent 8-week-long treatment as above; i.e. with $\mathrm{cHF}, \mathrm{cHF}+\mathrm{F}, \mathrm{cHF}+\mathrm{TZD}$ and $\mathrm{cHF}+\mathrm{F}+\mathrm{TZD}$, respectively.

During treatments, fresh rations of food were distributed daily. Food consumption and body weights were recorded once a week. Experiments were conducted under the guidelines for the use and care of laboratory animals of the Institute of Physiology and followed the 'Principles of laboratory animal care' (NIH publication no. 85-23, revised 1985).

Metabolites, hormones and enzymes Non-esterified fatty acids, triacylglycerols, total cholesterol and insulin were determined in EDTA-plasma [9]. Blood glucose was measured by calibrated glucometers (LifeScan, Milpitas, CA, USA). Total adiponectin was measured by ELISA [31] (R\&D Systems, Abingdon, UK). Distribution of adiponectin multimeric complexes was determined using western blotting [33].

\section{Body composition See ESM for details.}

Tissue lipid content Liver and muscle triacylglycerol content was estimated in ethanolic $\mathrm{KOH}$ tissue solubilisates
[32]. Ceramide content was estimated in lipid extracts from soleus muscle homogenates using HPLC [34].

Quantitative RT-PCR-based gene expression analysis Levels of various transcripts were evaluated in total RNA isolated from liver or gastrocnemius muscle [10]. For primers, see ESM Table 3.

Glycogen synthesis in diaphragm Left and right hemidiaphragms were dissected and separately incubated ex vivo to measure incorporation of glucose into glycogen, as previously described [35] (see ESM).

In vivo hepatic VLDL-triacylglycerol production The rate of liver triacylglycerol synthesis was evaluated using Triton WR1339 [36] and calculated from the slope of the curve of plasma triacylglycerol levels [37] (see ESM).

Light microscopy and immunohistochemical analysis Epididymal fat samples were processed to detect MAC-2/ galectin and perilipin, using specific antibodies $[32,38]$ (see ESM).

Glucose tolerance test Intraperitoneal glucose tolerance test was performed in fasted mice as described [32].

Euglycaemic-hyperinsulinaemic clamp This was performed as described (ESM) [39-41].

Activation of protein kinase $B$ Phosphorylation of protein kinase $\mathrm{B}(\mathrm{Akt} / \mathrm{PKB})$ was measured in soleus muscles using western blots (ESM Fig. 1).

Statistics Data were analysed by ANOVA and $t$ test, as described in ESM. All values are presented as means \pm SE. Comparisons were judged to be significant at $p \leq 0.05$.

\section{Results}

Prevention of body weight gain and lipid accumulation Body weight was increased by cHF diet with significant differences between chow and cHF becoming apparent at 4 weeks (Fig. 1a). Treatment by $\mathrm{cHF}+\mathrm{F}$ or by $\mathrm{cHF}+\mathrm{TZD}$ diets tended to prevent body weight gain (Fig. 1a). The combination treatment, $\mathrm{cHF}+\mathrm{F}+\mathrm{TZD}$, reduced body weight gain significantly (Fig. 1a). The same pattern of body weight gain continued throughout the duration of the study, which lasted for 20 weeks. None of the diets affected mean food consumption over the course of the study (Fig. 1b). Body composition was analysed at 15 weeks (Fig. 1c), i.e. when the effect of $\mathrm{cHF}+\mathrm{F}+\mathrm{TZD}$ diet on 

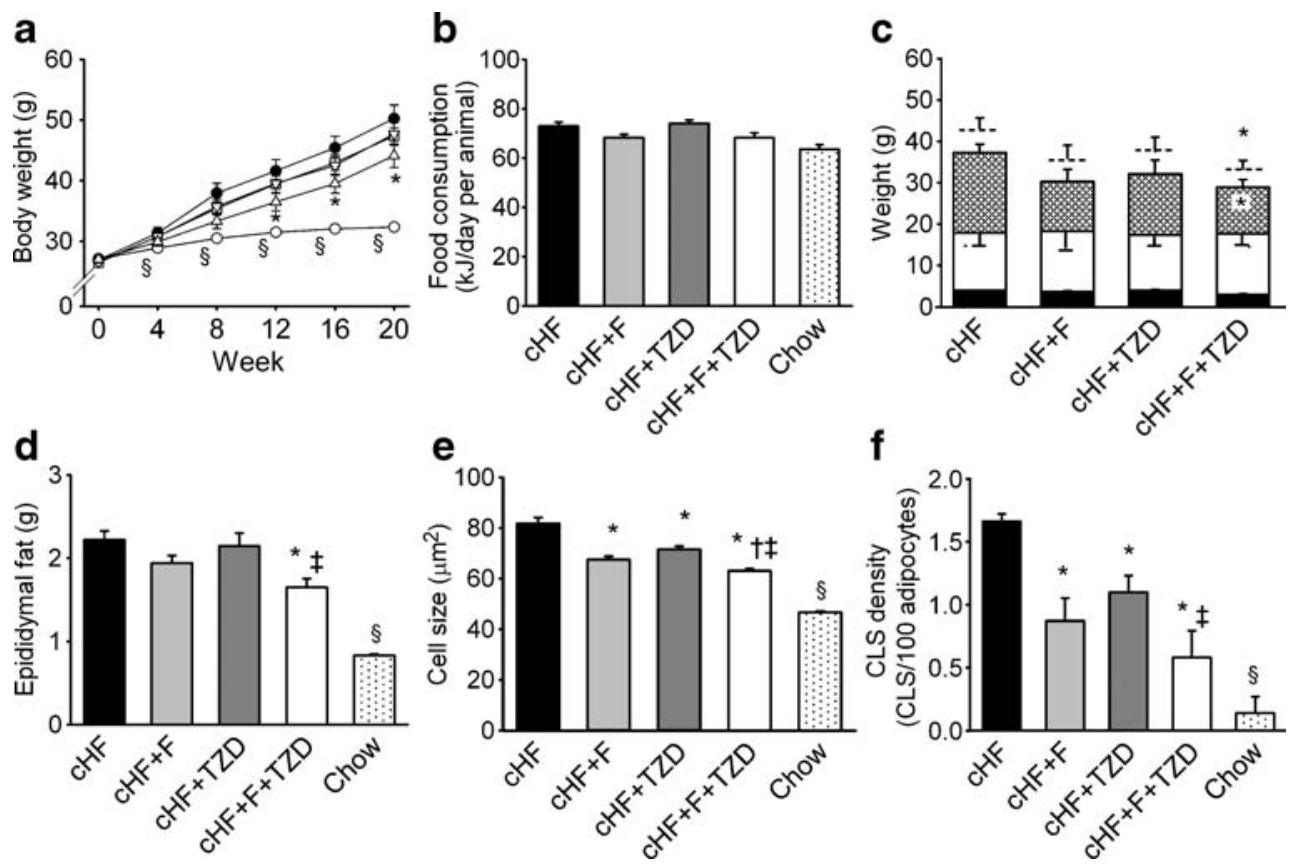

Fig. 1 Body weight (a), food consumption (b), body composition and size of adipocytes (c-e), and macrophage infiltration of adipose tissue (f). Three-month-old mice were placed on $\mathrm{cHF}$ diet or various cHF-based diets $(\mathrm{cHF}+\mathrm{F}, \mathrm{cHF}+\mathrm{TZD}$ and $\mathrm{cHF}+\mathrm{F}+\mathrm{TZD})$, or maintained on a chow diet; this treatment lasted for up to 20 weeks. a Body weights during 20-week treatment by $\mathrm{cHF}$ (black circles), $\mathrm{cHF}+\mathrm{F}$ (white squares), cHF+TZD (white inverted triangles), $\mathrm{cHF}+\mathrm{F}+\mathrm{TZD}$ (white triangles) or chow (white circles) diet $(n=16)$. b Mean food consumption during 20 week treatment $(n=8)$. c Body composition at 15 weeks. Bar height, weight of eviscerated carcass; black section, protein; white + black sections, lean body mass; cross-hatched section, fat; dashed horizontal lines above bars, body weight of mice before killing. Error bars, SE $(n=5-6)$. d Epididymal fat at 8 weeks, weight of fat depot. e Size of adipocytes. f Relative count of crown-like structures (CLS), formed by MAC-2-positive macrophages surrounding adipocytes. The morphometry data are based on measurements of more than 1,000 cells taken randomly from six different areas per animal. d-f Data are means \pm SE $(n=7-8) .{ }^{*} p \leq 0.05$ for difference from $\mathrm{cHF}$ (ANOVA); ${ }^{\dagger} p \leq 0.05$ for difference from $\mathrm{cHF}+\mathrm{F}$ (ANOVA); ${ }^{\ddagger} p \leq 0.05$ for difference from $\mathrm{cHF}+\mathrm{TZD}$ (ANOVA); ${ }^{\S_{p} \leq 0.05 \text { for }}$ difference from $\mathrm{cHF}(t$ test)

respective diets. No differences in physical activity between the groups were detected (not shown).

Given the induction of weight gain by rosiglitazone in previous studies on rodents, the induction of a lean phenotype by the cHF+TZD, and especially by the $\mathrm{cHF}+\mathrm{F}+\mathrm{TZD}$ diets was surprising and is, perhaps, related to higher doses of rosiglitazone used in other studies [24, 27]. Indeed, when rosiglitazone content in the diet was increased tenfold (i.e. from 10 to $100 \mathrm{mg}$ rosiglitazone per $\mathrm{kg}$ diet), this increase was associated with higher body weight gain as early as 4 weeks after initiation of the feeding $(26.3 \pm$ $0.8 \mathrm{~g}$ vs $28.5 \pm 0.5 \mathrm{~g} ; n=8 ; p=0.04$ ).

Compared with standard chow, the cHF diet induced accumulation of triacylglycerols in liver and gastrocnemius, a mixed-fibre muscle, with a stronger effect observed at 20 than at 8 weeks (Table 1). Compared with cHF, none of the treatments significantly affected the triacylglycerol accumulation, except for $\mathrm{cHF}+\mathrm{TZD}$, which increased liver triacylglycerols at 8 weeks. The $\mathrm{cHF}+\mathrm{F}+\mathrm{TZD}$ diet also increased liver triacylglycerol content at 8 weeks, albeit to a smaller extent (Table 1). No differences in the triacylglycerol content between subgroups were observed in soleus, 
Table 1 Lipid accumulation in liver and skeletal muscle

Data are means \pm SE $(n=7-8)$

Mice (3 months old) were placed on various diets and killed in ad libitum fed state, after 8 or 20 weeks on the diets.

${ }^{\mathrm{a}} p \leq 0.05$ for difference from $\mathrm{cHF}$ (ANOVA); ${ }^{\mathrm{b}} p \leq 0.05$ for difference from $\mathrm{cHF}+\mathrm{F}$ (ANOVA); ${ }^{\mathrm{c}} p \leq 0.05$ for difference from cHF+TZD (ANOVA); ${ }^{d} p \leq 0.05$ for difference from $\mathrm{cHF}$ ( $t$ test)

\begin{tabular}{|c|c|c|c|c|c|}
\hline Tissue & $\mathrm{cHF}$ & $\mathrm{cHF}+\mathrm{F}$ & $\mathrm{cHF}+\mathrm{TZD}$ & $\mathrm{cHF}+\mathrm{F}+\mathrm{TZD}$ & Chow \\
\hline \multicolumn{6}{|c|}{ Liver triacylglycerol (mg/g) } \\
\hline 8 weeks & $80 \pm 15$ & $70 \pm 8$ & $197 \pm 23^{\mathrm{ab}}$ & $123 \pm 15^{\mathrm{b}}$ & $34 \pm 3^{\mathrm{d}}$ \\
\hline 20 weeks & $159 \pm 16$ & $153 \pm 11$ & $171 \pm 10$ & $153 \pm 15$ & $36 \pm 2^{\mathrm{d}}$ \\
\hline \multicolumn{6}{|c|}{ Gastrocnemius muscle triacylglycerol (mg/g) } \\
\hline 8 weeks & $39 \pm 4$ & $41 \pm 5$ & $41 \pm 6$ & $37 \pm 5$ & $18 \pm 2^{\mathrm{d}}$ \\
\hline 20 weeks & $56 \pm 3$ & $61 \pm 3$ & $50 \pm 4$ & $60 \pm 4$ & $25 \pm 3^{\mathrm{d}}$ \\
\hline \multicolumn{6}{|c|}{ Soleus muscle triacylglycerol (mg/g) } \\
\hline 20 weeks & $47 \pm 5$ & $51 \pm 3$ & $48 \pm 7$ & $50 \pm 2$ & $34 \pm 3$ \\
\hline \multicolumn{6}{|c|}{ Soleus muscle ceramide $(\mathrm{pmol} / \mathrm{g})$} \\
\hline 20 weeks & $17.9 \pm 0.8$ & $16.0 \pm 0.6$ & $17.2 \pm 0.5$ & $14.2 \pm 0.3^{\mathrm{ac}}$ & $16.6 \pm 0.5$ \\
\hline
\end{tabular}

an oxidative muscle, after the prolonged treatment. However, the $\mathrm{cHF}+\mathrm{F}+\mathrm{TZD}$ diet significantly lowered ceramide content in the soleus muscle as compared with cHF-fed mice (Table 1).

Prevention of dyslipidaemia and reduction of hepatic VLDL-triacylglycerol synthesis In ad libitum fed mice, triacylglycerol levels increased while NEFA and cholesterol levels remained unchanged between 8 and 20 weeks of cHF feeding (Table 2). Triacylglycerol and NEFA levels were significantly suppressed by $\mathrm{cHF}+\mathrm{F}+\mathrm{TZD}$, even below the levels observed in chow diet-fed mice. Cholesterol levels were reduced at 8 but not at 20 weeks. The other treatments $(\mathrm{cHF}+\mathrm{F}$ and $\mathrm{cHF}+\mathrm{TZD})$ induced smaller or no reduction of plasma lipid levels (Table 2).

We also investigated the effect of 8 weeks of treatment on liver VLDL-triacylglycerol synthesis (Fig. 2). Plasma triacylglycerol levels were measured in fasted mice just prior to and for $3 \mathrm{~h}$ after injection of Triton WR-1339. Under these conditions, the nonionic detergent blocks lipolytic degradation of triacylglycerol-rich lipoproteins in the peripheral tissues, with the rise in plasma triacylglycerols proportionate to production of VLDL in the liver. All the treatments significantly decreased the rate of VLDLtriacylglycerol synthesis, with the strongest reduction (approximately twofold) by $\mathrm{cHF}+\mathrm{F}+\mathrm{TZD}$.

Prevention of IGT and insulin resistance Insulinaemia increased between 8 and 20 weeks of high-fat feeding, suggesting development of insulin resistance (Table 2). The rise in insulin levels was prevented to a similar extent by $\mathrm{cHF}+\mathrm{TZD}$ and $\mathrm{cHF}+\mathrm{F}+\mathrm{TZD}$ diets, while the $\mathrm{cHF}+\mathrm{F}$ diet exhibited a significant but smaller effect.

Both at 8 and 20 weeks, the $\mathrm{cHF}+\mathrm{F}$ and $\mathrm{cHF}+\mathrm{TZD}$ diets increased total immunoreactive adiponectin in plasma. An even stronger induction was observed with a combination of the two treatments (Table 2). Multimeric adiponectin complexes in plasma were also analysed. Although the ratio between high molecular weight (HMW) and total adiponectin was similar in the cHF- and chow-fed mice, it was increased by all the other treatments, with the highest additive effect observed in $\mathrm{cHF}+\mathrm{F}+\mathrm{TZD}$-fed animals, irrespective of treatment duration (Table 2).

To characterise insulin sensitivity and glycaemic control, a glucose tolerance test was performed at 8 weeks (Fig. 3a). Fasted glycaemia was $\sim 1$-fold higher in the cHF- as compared with the chow-fed mice and was not significantly affected by any of the treatments (Fig. 3a, b). In contrast, feeding cHF resulted in IGT, as revealed by $\sim 1$.4-fold higher AUC values (glucose tolerance test) in the cHF- compared with the chow-fed mice (Fig. 3c). Both cHF+TZD and $\mathrm{cHF}+\mathrm{F}+\mathrm{TZD}$ diets prevented development of IGT, while $\mathrm{cHF}+\mathrm{F}+\mathrm{TZD}$ displayed the largest improvements in glucose tolerance.

At 8 weeks, a euglycaemic-hyperinsulinaemic clamp was also performed to evaluate precisely the changes in wholebody insulin sensitivity brought about by various treatments (Fig. 3d-i). In the hyperinsulinaemic conditions, the amount of exogenous glucose required to maintain euglycaemia, i.e. the glucose infusion rate, was significantly $(\sim 1.7$-fold $)$ higher in mice treated by $\mathrm{cHF}+\mathrm{F}$ or $\mathrm{cHF}+\mathrm{TZD}$ than in cHF-fed mice (Fig. 3e), suggesting improvements in insulin sensitivity. Importantly, cHF+F+TZD resulted in a 2 .4fold higher glucose infusion rate than that in cHF-fed mice, representing the strongest effect among all the treatments. Hepatic glucose production in the hyperinsulinaemic conditions was decreased in the $\mathrm{cHF}+\mathrm{F}$ mice to a significantly lower level than in the other subgroups (Fig. 3f), suggesting that DHA/EPA improves hepatic insulin sensitivity. The $\mathrm{cHF}+\mathrm{F}+\mathrm{TZD}$ and $\mathrm{cHF}+\mathrm{TZD}$ (but not $\mathrm{cHF}+\mathrm{F}$ ) treatments significantly improved whole-body glucose turnover, with $\mathrm{cHF}+\mathrm{F}+\mathrm{TZD}$ showing the most dramatic effect (Fig. 3g). The rate of whole-body glycolysis was not significantly affected by the treatments (Fig. 3h). Whole-body glycogen synthesis was strongly stimulated by $\mathrm{cHF}+\mathrm{F}+\mathrm{TZD}$, while $\mathrm{cHF}+\mathrm{F}$ and $\mathrm{cHF}+\mathrm{TZD}$ diets had no effect (Fig. 3i). No 
Table 2 Prevention of dyslipidaemia and hyperinsulinaemia, and induction of adiponectin

\begin{tabular}{|c|c|c|c|c|c|}
\hline Variable & $\mathrm{cHF}$ & $\mathrm{cHF}+\mathrm{F}$ & $\mathrm{cHF}+\mathrm{TZD}$ & $\mathrm{cHF}+\mathrm{F}+\mathrm{TZD}$ & Chow \\
\hline \multicolumn{6}{|l|}{8 weeks } \\
\hline Triacylglycerol $(\mathrm{mmol} / \mathrm{l})$ & $1.3 \pm 0.1$ & $1.1 \pm 0.1$ & $1.0 \pm 0.1$ & $0.8 \pm 0.1^{\mathrm{ab}}$ & \\
\hline NEFA $(\mathrm{mmol} / \mathrm{l})$ & $0.49 \pm 0.05$ & $0.43 \pm 0.04$ & $0.38 \pm 0.03^{\mathrm{a}}$ & $0.27 \pm 0.02^{\mathrm{abc}}$ & \\
\hline Cholesterol (mmol/l) & $3.7 \pm 0.2$ & $3.2 \pm 0.2^{\mathrm{a}}$ & $3.8 \pm 0.1^{\mathrm{b}}$ & $3.1 \pm 0.1^{\mathrm{ab}}$ & \\
\hline Insulin $(\mathrm{pmol} / \mathrm{l})$ & $330 \pm 60$ & $210 \pm 30$ & $270 \pm 30$ & $165 \pm 45^{\mathrm{a}}$ & \\
\hline Adiponectin $(\mu \mathrm{g} / \mathrm{ml})$ & $8.6 \pm 0.4$ & $11.0 \pm 0.5$ & $10.3 \pm 0.2$ & $12.3 \pm 0.7^{\mathrm{a}}$ & \\
\hline HMW:total & $0.27 \pm 0.02$ & $0.30 \pm 0.03$ & $0.35 \pm 0.02^{\mathrm{a}}$ & $0.41 \pm 0.01^{\mathrm{abc}}$ & \\
\hline \multicolumn{6}{|l|}{20 weeks } \\
\hline Triacylglycerol (mmol/l) & $2.1 \pm 0.1$ & $1.8 \pm 0.2$ & $1.5 \pm 0.1^{\mathrm{a}}$ & $1.1 \pm 0.1^{\mathrm{ab}}$ & $1.3 \pm 0.1^{\mathrm{d}}$ \\
\hline NEFA (mmol/l) & $0.50 \pm 0.03$ & $0.35 \pm 0.07^{\mathrm{a}}$ & $0.41 \pm 0.03$ & $0.29 \pm 0.02^{\mathrm{ac}}$ & $0.49 \pm 0.03$ \\
\hline Cholesterol (mmol/l) & $4.4 \pm 0.2$ & $3.7 \pm 0.1^{\mathrm{a}}$ & $3.8 \pm 0.2$ & $3.7 \pm 0.2$ & $2.1 \pm 0.1^{\mathrm{d}}$ \\
\hline Insulin $(\mathrm{pmol} / \mathrm{l})$ & $1125 \pm 165$ & $630 \pm 120^{\mathrm{a}}$ & $360 \pm 45^{\mathrm{ab}}$ & $270 \pm 30^{\mathrm{ab}}$ & $90 \pm 15^{\mathrm{d}}$ \\
\hline Adiponectin $(\mu \mathrm{g} / \mathrm{ml})$ & $5.3 \pm 0.3$ & $8.2 \pm 0.6^{\mathrm{a}}$ & $8.6 \pm 0.4^{\mathrm{a}}$ & $10.1 \pm 0.4^{\mathrm{abc}}$ & $4.4 \pm 0.3$ \\
\hline HMW:total & $0.33 \pm 0.03$ & $0.46 \pm 0.01^{\mathrm{a}}$ & $0.49 \pm 0.02^{\mathrm{a}}$ & $0.55 \pm 0.02^{\mathrm{ab}}$ & $0.34 \pm 0.02$ \\
\hline
\end{tabular}

Mice ( 3 months old) were placed on various diets, and after 8 or 20 weeks of treatment lipid metabolites and hormones were measured in plasma of mice killed in ad libitum fed state. Data are means $\pm \operatorname{SE}(n=8)$

${ }^{\mathrm{a}} p \leq 0.05$ for difference from cHF (ANOVA); ${ }^{\mathrm{b}} p \leq 0.05$ for difference from $\mathrm{cHF}+\mathrm{F}$ (ANOVA); ${ }^{\mathrm{c}} p \leq 0.05$ for difference from cHF+TZD (ANOVA); d $p \leq 0.05$ for difference from $\mathrm{cHF}(t$ test $)$

HMW:total; ratio of HMW:total adiponectin

differences in muscle glycogen content between groups were observed (not shown).

Muscle- and liver-specific effects of the treatments To confirm the results on whole-body glycogen synthesis, measurements were also performed ex vivo, in dissected diaphragms from mice subjected to various treatments (Fig. 4). Diaphragm contains glycolytic and oxidative muscle fibres and is suitable for this type of analysis due to its small diffusion barrier for oxygen [42]. Compared with chow, cHF reduced the rate of basal $(\sim 2.5$-fold $)$ and insulin-stimulated ( 2.8-fold) glycogen synthesis. This deleterious effect of cHF feeding was completely prevented by $\mathrm{cHF}+\mathrm{F}+\mathrm{TZD}$ (Fig. 4). Neither $\mathrm{cHF}+\mathrm{F}$ nor $\mathrm{cHF}+\mathrm{TZD}$ had any significant effect on basal or insulin-stimulated glycogen synthesis. Improvements in insulin-stimulated glycogen synthesis also correlated with the induction of Akt/PKB phosphorylation at Ser473 in soleus muscle of mice fed $\mathrm{cHF}+\mathrm{F}+\mathrm{TZD}$ (ESM Fig. 1).

Analysis of gene expression from gastrocnemius, a mixed-fibre muscle, revealed a trend (Fig. 5a) for induction by the combination treatment of Pdk4, Cptla and Cpt1b, supporting the notion that the combination treatment induced a switch augmenting lipid over glucose catabolism. Interestingly, the $\mathrm{cHF}+\mathrm{TZD}$ diet strongly induced expression of $S c d 1$, while $\mathrm{cHF}+\mathrm{F}$ and $\mathrm{cHF}+\mathrm{F}+\mathrm{TZD}$ treatments had an opposite effect.

Analysis of hepatic gene expression (Fig. 5b) revealed a downregulation of gluconeogenic genes Pck2 and G6pc by $\mathrm{cHF}+\mathrm{F}+\mathrm{TZD}$, while $\mathrm{cHF}+\mathrm{F}$ and $\mathrm{cHF}+\mathrm{TZD}$ diets exerted less pronounced effects. The $\mathrm{cHF}+\mathrm{F}+\mathrm{TZD}$ diet strongly induced expression of Acot2, in correlation with upregulation of $C p t 1 b$, suggesting increased turnover of acyl-CoA and fatty acid oxidation in mitochondria. A similar pattern of induction of Acoxl, a marker of peroxisomal fatty acid oxidation, was observed. Both $\mathrm{cHF}+\mathrm{TZD}$ and $\mathrm{cHF}+\mathrm{F}+\mathrm{TZD}$ strongly induced expression of $S c d 1$, while $\mathrm{cHF}+\mathrm{F}$ had no effect. In contrast, Fas was downregulated by $\mathrm{cHF}+\mathrm{F}$ and $\mathrm{cHF}+\mathrm{F}+\mathrm{TZD}$, while $\mathrm{cHF}+\mathrm{TZD}$ had no effect.

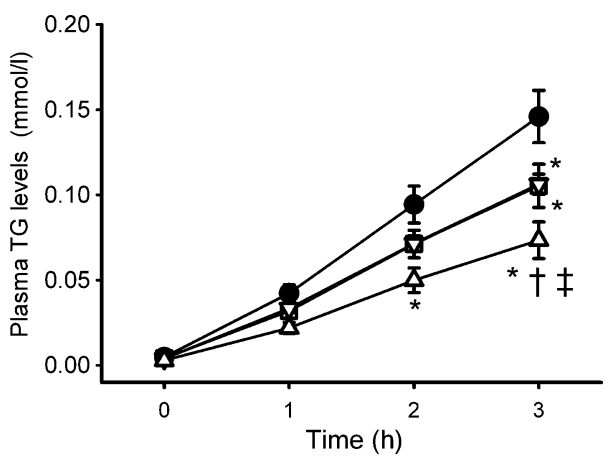

Fig. 2 Hepatic VLDL-triacylglycerol production. At 3 months of age, mice were randomly assigned to various diets. After 8 weeks of treatment, mice were fasted for $6 \mathrm{~h}$, anaesthetised, injected with Triton WR1339 and plasma triacylglycerol (TG) levels were measured before (time 0 ) and at 1,2 and $3 \mathrm{~h}$ after injection in mice fed cHF (black circles), $\mathrm{cHF}+\mathrm{F}$ (white squares), $\mathrm{cHF}+\mathrm{TZD}$ (white inverted triangles) and $\mathrm{cHF}+\mathrm{F}+\mathrm{TZD}$ (white triangles). Data are means $\pm \mathrm{SE}(n=5-8)$. ${ }^{*} p \leq 0.05$ for difference from $\mathrm{cHF} ;{ }^{\dagger} p \leq 0.05$ for difference from $\mathrm{cHF}+\mathrm{F}$; ${ }^{\ddagger} p \leq 0.05$ for difference from cHF+TZD (repeated measures ANOVA) 
Fig. 3 Glucose homeostasis. At 8 weeks after treatment as described, glucose tolerance test $(\mathbf{a}-\mathbf{c})$ or euglycaemichyperinsulinaemic clamp (d-i) were performed in two separate experiments. a Plasma glucose levels following intraperitoneal glucose injection (time 0 ) to fasted mice treated by $\mathrm{cHF}$ (black circles), $\mathrm{cHF}+\mathrm{F}$ (white squares), cHF+TZD (white inverted triangles), $\mathrm{cHF}+\mathrm{F}+\mathrm{TZD}$ (white triangles) or chow (white circles). b Fasted blood glucose (FBG) levels at time 0 as above (a). c

Area under the glycaemic curve values as above (a). d Mean plasma glucose levels during euglycaemic-hyperinsulinaemic clamp. e-h Variables, as indicated, that were evaluated during stimulation by insulin. Data are means \pm SE $(n=6-9)$. ${ }^{*} p \leq 0.05$ for difference from $\mathrm{cHF} ;{ }^{\dagger} p \leq 0.05$ for difference from $\mathrm{cHF}+\mathrm{F} ;{ }^{\star} p \leq 0.05$ for difference from $\mathrm{cHF}+\mathrm{TZD}$ (ANOVA); ${ }^{\S} p \leq 0.05$ for difference from $\mathrm{cHF}$ ( $t$ test). GIR, glucose infusion rate; GTO, glucose turnover: HGP, hepatic glucose production
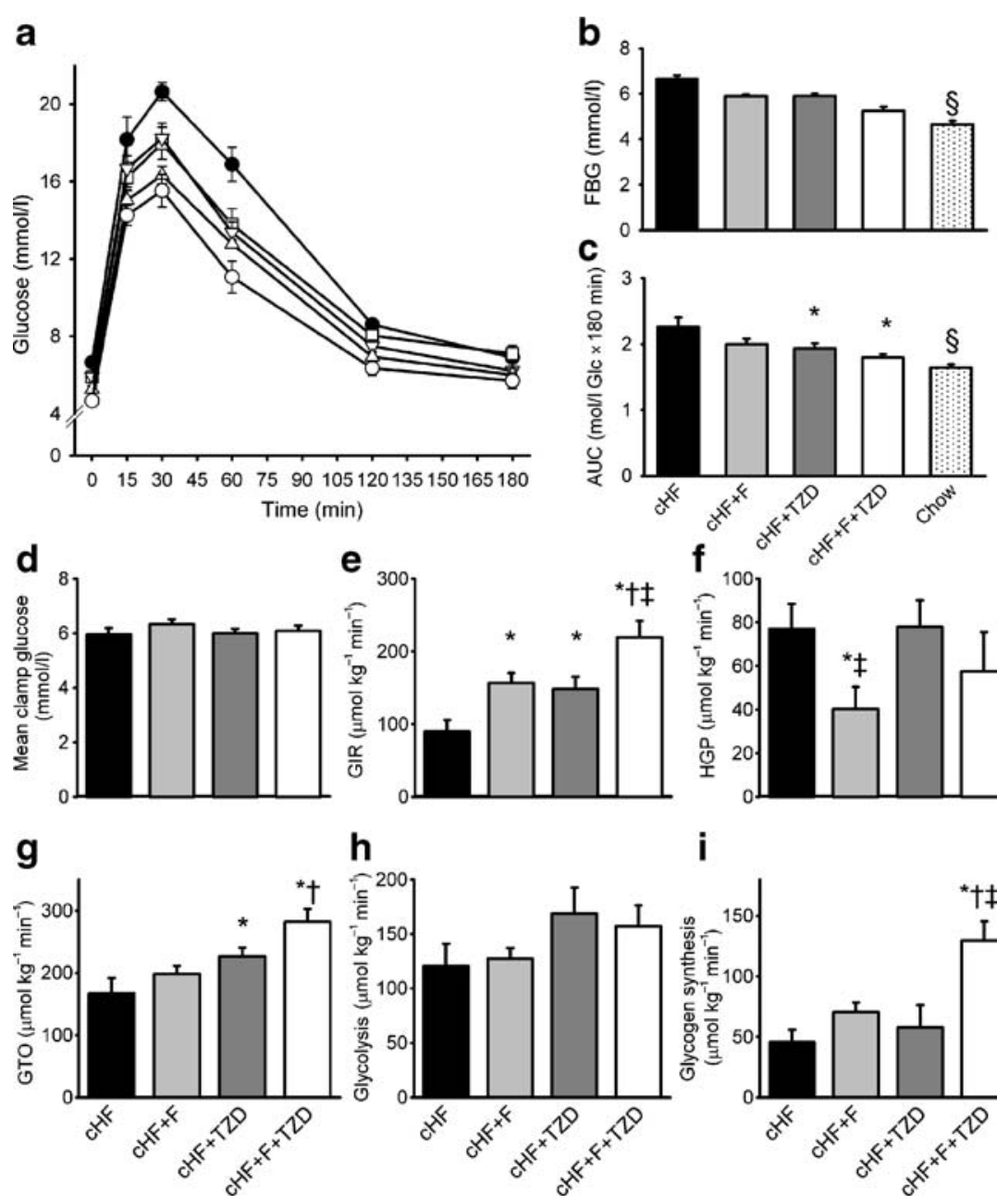

i

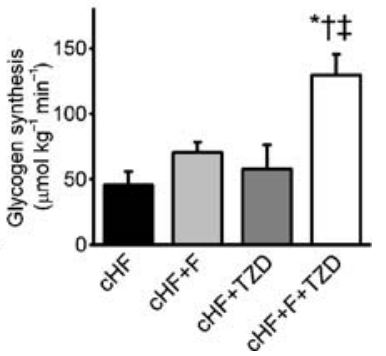

Interestingly, no adverse effects of the combination treatment on enzymatic markers of muscle and liver damage were observed (ESM Table 4).

Reversal of obese phenotype Given both the high efficacy of the $\mathrm{cHF}+\mathrm{F}+\mathrm{TZD}$ treatment in prevention of the highfat diet-induced disorders in mice and the failure of $n-3$ LC-PUFA to reverse insulin resistance in humans (see Introduction), the effects of $\mathrm{cHF}+\mathrm{F}$ and $\mathrm{cHF}+\mathrm{TZD}$ and their combination were also studied in obese mice with IGT (Table 3). Compared with cHF-fed animals, body weight gain, triacylglycerols and NEFA levels were suppressed by $\mathrm{cHF}+\mathrm{F}$, while $\mathrm{cHF}+\mathrm{TZD}$ decreased plasma triacylglycerols and insulin levels. Only $\mathrm{cHF}+\mathrm{F}+\mathrm{TZD}$ affected all the variables studied, showing additive effects of DHA/EPA and rosiglitazone in the reversal of obesity, while decreasing plasma NEFA and cholesterol levels. The $\mathrm{cHF}+\mathrm{F}+\mathrm{TZD}$ diet also lowered plasma triacylglycerol and insulin concentrations, to a similar extent to that achieved by cHF+TZD (Table 3 ).

To evaluate the capacity of treatments to reverse IGT in dietary obese mice, a glucose tolerance test was performed 1 week before the end of the study. Fasting glycaemia was decreased to a similar extent by all treatments (Table 3). However, glucose tolerance measured as AUC was markedly improved by $\mathrm{cHF}+\mathrm{F}+\mathrm{TZD}$, indicating additive effects of DHA/EPA and rosiglitazone in the reversal of IGT. Both $\mathrm{cHF}+\mathrm{F}$ and $\mathrm{cHF}+\mathrm{TZD}$ improved glucose tolerance, but to a smaller extent than $\mathrm{cHF}+\mathrm{F}+\mathrm{TZD}$ (Table 3).

\section{Discussion}

Combination of life style changes with pharmacological interventions is required for treatment of diabetes and other metabolic diseases associated with obesity. However, safer, more efficacious and less expensive strategies are still needed. We show here that long-term treatment combining partial replacement of dietary lipids by DHA/EPA and a low dose of rosiglitazone markedly and in an additive manner prevented development of dyslipidaemia and insulin resistance, reduced accumulation of body fat and adipocyte hypertrophy, and also induced adiponectin in mice fed a high-fat diet. Importantly, this treatment also reversed IGT in obese mice. 


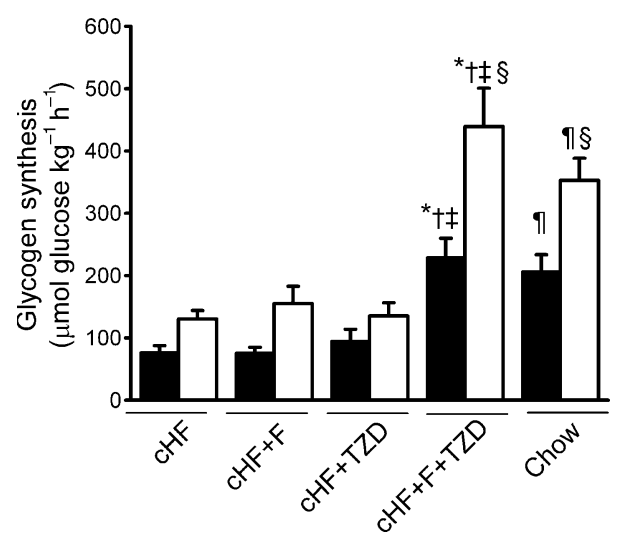

Fig. 4 Glycogen synthesis in diaphragm muscle. At 5 weeks after initiation of treatment as described, left and right hemidiaphragms of mice were dissected and incubated with $\left[\mathrm{U}^{14} \mathrm{C}\right]$ glucose in the absence (black bars) or presence (white bars) of $250 \mu \mathrm{U} / \mathrm{ml}$ insulin to measure the rate of glycogen synthesis. Data are means \pm SE $(n=7-8) .{ }^{*} p \leq 0.05$ for difference from cHF; $\dagger p \leq 0.05$ for difference from $\mathrm{cHF}+\mathrm{F} ;{ }^{\ddagger} p \leq$ 0.05 for difference from $\mathrm{cHF}+\mathrm{TZD}$ (ANOVA); ${ }^{\S} p \leq 0.05$ for difference from non-insulin-stimulated value within the $\operatorname{diet}\left(\right.$ ANOVA); ${ }^{\natural} p \leq 0.05$ for difference from cHF ( $t$ test)

As described before $[9,10]$, DHA/EPA reduced fat accumulation, without affecting food consumption. Unexpectedly, a relatively low dose of rosiglitazone $(10 \mathrm{mg}$ rosiglitazone per $\mathrm{kg}$ diet) was sufficient to augment the induction of lean phenotype by DHA/EPA. In contrast, at a tenfold higher dose, rosiglitazone promoted obesity, as observed in most other studies in mice [24, 27]. In humans, rosiglitazone therapy reduced abdominal and increased subcutaneous fat weight [20]. However, weight of both fat depots in mice was decreased by the combination treatment of DHA/EPA with rosiglitazone, suggesting that treatment by a low dose of rosiglitazone combined with dietary $n-3$ LC-PUFA intake may also reduce adiposity in humans.

Indirect calorimetry in mice did not reveal any differences in fuel partitioning or energy expenditure between groups. In addition, no difference in physical activity was detected. Therefore, the mechanism for reduced body weight gain in the $\mathrm{cHF}+\mathrm{F}+\mathrm{TZD}$-treated mice remains unclear. However, even small undetectable changes in the above variables (or in food intake) or their combination, lasting for several weeks, could result in a substantial difference in body weight.

It has been observed previously that treatment by DHA/ EPA or rosiglitazone ameliorated adipocyte hypertrophy [9, 43]. In line with these observations, the greatest reduction of adipocyte hypertrophy was observed with the combination of DHA/EPA and rosiglitazone. Compared with large adipocytes, small cells are more insulin-sensitive and less lipolytic, while releasing fewer inflammatory cytokines, as reviewed [20], and more adiponectin [44]. While treatment with DHA/EPA [15, 31] or TZD [15, 25] has previously been shown to induce adiponectin in mice, the current study showed for the first time that the combination of the two increased plasma adiponectin more potently. Importantly, the stimulatory effect of the combination treatment was specific for HMW adiponectin, the form of adiponectin associated with insulin sensitivity [33, 45]. Importantly, the combination treatment also reduced most potently the lowgrade adipose tissue inflammation associated with obesity
Fig. 5 Quantitative RT-PCR data showing gene expression in mouse gastrocnemius muscle (a) and liver (b) after 8 weeks of dietary treatments. Black bars, cHF; light grey bars, $\mathrm{cHF}+\mathrm{F}$; dark grey bars, cHF+TZD; white bars, $\mathrm{cHF}+\mathrm{F}+\mathrm{TZD}$. Data are means \pm SE $(n=6-7)$. $* p \leq 0.05$ for difference from $\mathrm{cHF}$ (ANOVA); ${ }^{\dagger} p \leq 0.05$ for difference from $\mathrm{cHF}+\mathrm{F}$ (ANOVA); ${ }^{\star} p \leq 0.05$ for difference from $\mathrm{cHF}+\mathrm{TZD}$ (ANOVA)

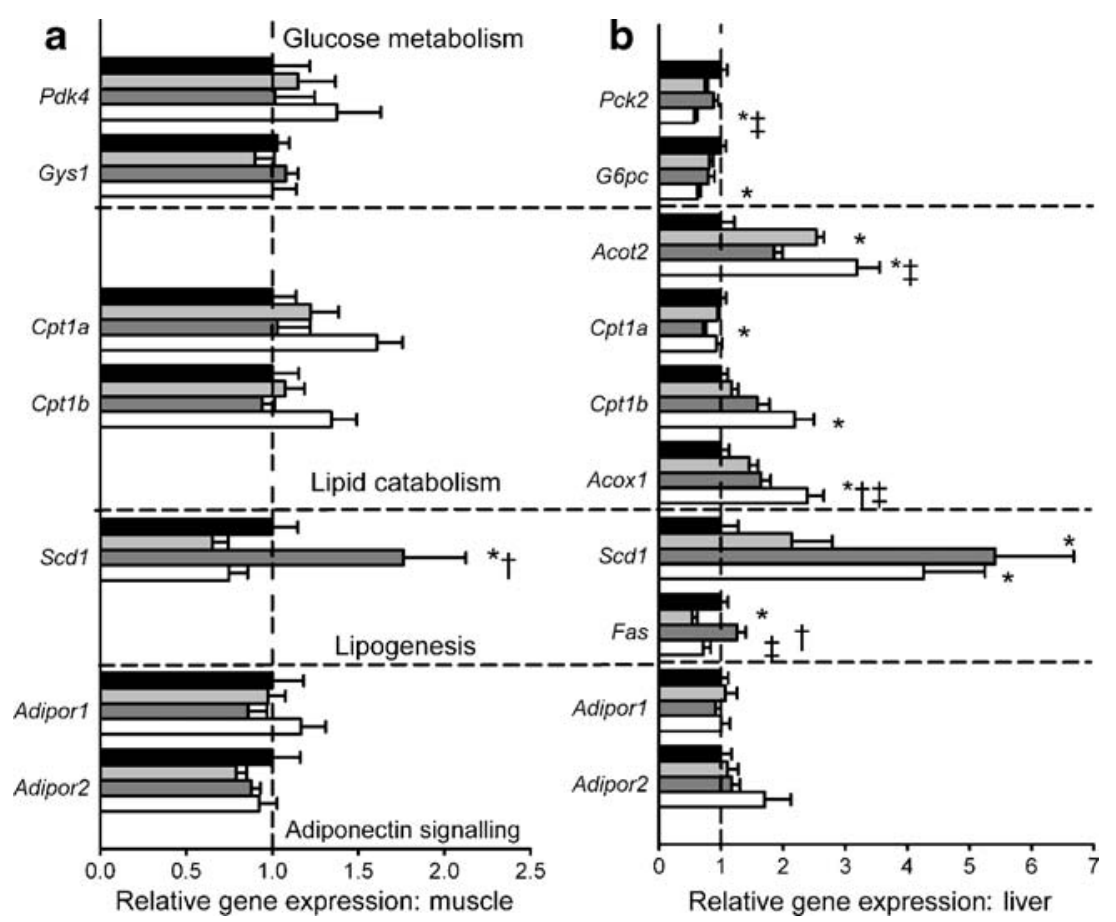


Table 3 Reversal of obesity, dyslipidaemia and impaired glucose homeostasis

\begin{tabular}{|c|c|c|c|c|}
\hline Variables & $\mathrm{cHF}$ & $\mathrm{cHF}+\mathrm{F}$ & $\mathrm{cHF}+\mathrm{TZD}$ & $\mathrm{cHF}+\mathrm{F}+\mathrm{TZD}$ \\
\hline \multicolumn{5}{|l|}{ Body weight } \\
\hline Initial (g) & $43.2 \pm 2.4$ & $43.3 \pm 2.2$ & $45.0 \pm 2.0$ & $44.9 \pm 1.7$ \\
\hline Final (g) & $47.3 \pm 2.4$ & $43.0 \pm 2.2$ & $47.5 \pm 1.7$ & $41.8 \pm 1.3$ \\
\hline Gain (g) & $4.1 \pm 1.0$ & $-0.3 \pm 1.0^{\mathrm{a}}$ & $2.5 \pm 1.1$ & $-3.1 \pm 1.8^{\mathrm{abc}}$ \\
\hline \multicolumn{5}{|l|}{ Plasma lipids and insulin } \\
\hline Triacylglycerols (mmol/l) & $1.34 \pm 0.16$ & $0.90 \pm 0.10^{\mathrm{a}}$ & $0.94 \pm 0.03^{\mathrm{a}}$ & $0.84 \pm 0.08^{\mathrm{a}}$ \\
\hline NEFA $(\mathrm{mmol} / \mathrm{l})$ & $0.46 \pm 0.04$ & $0.36 \pm 0.03^{\mathrm{a}}$ & $0.40 \pm 0.02$ & $0.27 \pm 0.03^{\mathrm{abc}}$ \\
\hline Cholesterol (mmol/l) & $5.10 \pm 0.36$ & $3.94 \pm 0.15$ & $4.02 \pm 0.48$ & $3.24 \pm 0.34^{\mathrm{a}}$ \\
\hline Insulin (pmol/l) & $510 \pm 54$ & $356 \pm 80$ & $285 \pm 74^{\mathrm{a}}$ & $215 \pm 33^{\mathrm{a}}$ \\
\hline \multicolumn{5}{|l|}{ Glucose tolerance test } \\
\hline $\mathrm{FBG}(\mathrm{mmol} / \mathrm{l})$ & $7.49 \pm 0.55$ & $5.94 \pm 0.22^{\mathrm{a}}$ & $5.88 \pm 0.55^{\mathrm{a}}$ & $5.22 \pm 0.22^{\mathrm{a}}$ \\
\hline $\operatorname{AUC}\left(\mathrm{mmol} \mathrm{l}{ }^{-1} \times 180 \mathrm{~min}\right)$ & $3,404 \pm 201$ & $2,739 \pm 136^{\mathrm{a}}$ & $2,592 \pm 161^{\mathrm{a}}$ & $2,109 \pm 124^{\mathrm{abc}}$ \\
\hline
\end{tabular}

Data are means \pm SE $(n=8)$

To induce obesity and IGT, mice were fed cHF diet between 3 and 7 months of age, and then treated by different diets for 8 more weeks. Body weight was recorded just before and at the end of the 8-week-treatment. After the treatment, plasma lipids and insulin were measured in ad libitum fed mice. Glucose tolerance test was performed in fasted mice 7 weeks after initiation of treatment

${ }^{\mathrm{a}} p \leq 0.05$ for difference from $\mathrm{cHF} ;{ }^{\mathrm{b}} p \leq 0.05$ for difference from $\mathrm{cHF}+\mathrm{F} ;{ }^{\mathrm{c}} p \leq 0.05$ for difference from $\mathrm{cHF}+\mathrm{TZD}$ (ANOVA)

FBG, fasting blood glucose

[24, 38]. Thus, the additive effects of DHA/EPA and rosiglitazone in the reduction of fat cell hypertrophy, induction of HMW adiponectin and decrease of adipose tissue inflammation might contribute to the beneficial effects on glucose homeostasis.

In a previous study [24], dual pharmacological activation of PPAR- $\alpha$ (by Wy-14,643) and PPAR- $\gamma$ (by rosiglitazone) in mice improved insulin sensitivity with increased efficacy compared with treatment by either PPAR agonist alone, while increasing both adiponectin and adiponectin receptors in adipose tissue [24]. In our experiments, the treatments did not significantly affect expression of adiponectin receptor genes Adipor1 and Adipor2, either in muscle or in liver, while DHA/EPA and rosiglitazone still improved insulin sensitivity in an additive manner. Importantly, in our experiments, naturally occurring $n-3$ LC-PUFA rather than synthetic PPAR- $\alpha$ agonists were used in the combination with a relatively low dose of rosiglitazone.

Euglycaemic-hyperinsulinaemic clamps in mice and ex vivo measurements in diaphragm muscle showed synergistic induction of glycogen synthesis at the basal and insulinstimulated conditions by the combination treatment, indicating that skeletal muscle was the major organ responsible for the additive effects of DHA/EPA and rosiglitazone on whole-body glycaemic control. Interestingly, and in accordance with previous studies, neither treatment by DHA/EPA [11, 12, 18], nor rosiglitazone alone (at the relatively low dose used) [23], significantly affected the rate of glycogen synthesis [34]. Increased insulin sensitivity of skeletal muscle is further supported by changes in Akt/PKB phosphorylation. A putative mechanism behind the synergistic effect of the combination treatment is reduction of muscle ceramide concentration. Interestingly, improvements in glucose homeostasis by the treatments became more pronounced with a longer duration of cHF feeding, despite the absence of any effect on triacylglycerol accumulation in the liver and muscle. This observation is not without precedent [12].

In accordance with previous studies, DHA/EPA [11, 12, 18], but not the low dose of rosiglitazone [23], were able to depress hepatic glucose production under hyperinsulinaemic conditions, suggesting improvement of hepatic insulin sensitivity by the former treatment. Given the ability of $n$ 3 LC-PUFA to prevent development of IGT, the above data also suggest that the effect on hepatic glucose production mentioned above may be required for this protection to occur. On the other hand, the reversal of IGT and insulin resistance by TZDs may be more dependent on the enhancing of insulin action in skeletal muscle. The latter mechanism could be mediated either by TZDs, or even more potently, according to our results, by the combination of DHA/EPA and TZDs.

The additive improvement of glycaemic control correlated with the hypolipidaemic effect of the treatments. Plasma levels of NEFA and triacylglycerols were even lower in mice treated by $\mathrm{cHF}+\mathrm{F}+\mathrm{TZD}$ than in mice fed chow diet, in spite of the higher dietary supply of lipids and the adipose tissue content of the former mice. These results are in accordance with the known hypolipidaemic effects of $n-3$ LC-PUFA [1] and rosiglitazone [25] in mice. Interest- 
ingly, in humans, only pioglitazone but not rosiglitazone exerted a hypolipidaemic effect [19], documenting that the hypolipidaemic effect of TZDs may be dissociated from their effect on insulin sensitivity [25].

The lowering of NEFA levels in mice subjected to various treatments could reflect several mechanisms, including adipose tissue lipolysis, re-esterification of NEFA in liver and adipose tissue, and stimulation of lipid oxidation in liver [14] and other organs [10] by $n-3$ LCPUFA, as well as by TZDs [26, 27]. The fact that $n-3$ LCPUFAs are able to counteract the inhibition of hepatic fatty acid oxidation by insulin [46] may contribute to the additive effect of the DHA/EPA and rosiglitazone treatment on lipid catabolism. The suppression of plasma triacylglycerol levels possibly resulted from an increased triacylglycerol uptake by muscle and other tissues induced by TZDs [47] and by $n-3$ LC-PUFA [48], or from decreased hepatic VLDL-triacylglycerol production. The former mechanism was not studied in our experiments; however, we did demonstrate the inhibition of hepatic VLDL-triacylglycerol production by either DHA/EPA or rosiglitazone, with the strongest effect being observed in the combination treatment. The decrease of hepatic triacylglycerol production by DHA/EPA may represent a functional outcome of the coordinated suppression of lipogenic genes by $n-3$ LC-PUFA [17]. In addition, stimulation of AMP-activated protein kinase by $n-3$ LC-PUFA, resulting in a metabolic switch from lipogenesis to lipid catabolism, may also be involved [49].

In contrast, the mechanism of suppression of VLDLtriacylglycerol formation by rosiglitazone must be different, since rosiglitazone increased $S c d 1$ expression and triacylglycerol content in the liver. The mechanism may reflect an increased rate of fatty acid re-esterification induced by rosiglitazone [50], rather than suppression of de novo lipogenesis in hepatocytes. Our data, in accordance with the effects of the treatments on muscle $S c d 1$, document differential modulation of the genes involved in de novo fatty acid synthesis (Fas) and desaturation ( $S c d 1)$ by DHA/ EPA and rosiglitazone. The induction of $S C D 1$ expression and activity in association with insulin sensitisation by rosiglitazone has been observed before [29], but the underlying mechanism remains unknown.

In conclusion, an original combined treatment using $n-3$ LC-PUFA with low-dose rosiglitazone generated additive effects in the prevention as well as reversal of adipose tissue hypertrophy, hyperlipidaemia and impaired glycaemic control in mice fed an obesogenic diet. Multiple mechanisms underlined the beneficial whole-body effects of the combination treatment with a prominent synergistic stimulation of insulin-sensitive muscle glycogen synthesis. The combined use of $n-3$ LC-PUFA and TZDs thus represents a potential strategy for treatment of type 2 diabetes and other obesity-associated metabolic disorders.
The inclusion of $n-3$ PUFA in treatment with TZDs may reduce the dose requirement and the incidence of adverse side effects associated with the TZD-based therapy.

Acknowledgements This work was supported by the grants from the Czech Science Foundation (303/08/0664) and the Ministry of Education, Youth and Sports (1M6837805002, COST BMB0602OC08007) of the Czech Republic. Further support included grants from the European Commission (LSHM-CT-2004-005272, EXGENESIS) to J. Kopecky and V. Mohamed-Ali, and from EPAX AS (Norway), as well as research project AV0Z50110509. The authors thank B. Stankova and E. Tvrzicka for the analysis of fatty acid composition of dietary lipids.

Duality of interest The authors declare that there is no duality of interest associated with this manuscript.

\section{References}

1. Ruxton CH, Reed SC, Simpson Double Dagger MJ, Millington KJ (2004) The health benefits of omega-3 polyunsaturated fatty acids: a review of the evidence. J Hum Nutr Diet 17:449-459

2. MacLean CH, Konica WA, Morton SC et al (2004) Effects of omega-3 fatty acids on lipids and glycemic control in type II diabetes and the metabolic syndrome and on inflammatory bowel disease, rheumatoid arthritis, renal disease, systemic lupus erythematosus, and osteoporosis. Evid Rep Technol Assess (Summ) 89:1-4

3. Nettleton JA, Katz R (2005) n-3 long-chain polyunsaturated fatty acids in type 2 diabetes: a review. J Am Diet Assoc 105:428-440

4. Mori TA, Bao DQ, Burke V, Puddey IB, Watts GF, Beilin LJ (1999) Dietary fish as a major component of a weight-loss diet: effect on serum lipids, glucose, and insulin metabolism in overweight hypertensive subjects. Am J Clin Nutr 70:817-825

5. Couet C, Delarue J, Ritz P, Antoine J-M, Lamisse F (1997) Effect of dietary fish oil on body fat mass and basal fat oxidation in healthy adults. Int J Obes 21:637-643

6. Fasching P, Ratheiser K, Waldhausl W et al (1991) Metabolic effects of fish-oil supplementation in patients with impaired glucose tolerance. Diabetes 40:583-589

7. Pelikanova T, Kohout M, Valek J, Kazdova L, Base J (1993) Metabolic effects of omega-3 fatty acids in type 2 (non-insulindependent) diabetic patients. Ann NY Acad Sci 683:272-278

8. Ikemoto S, Takahashi M, Tsunoda N, Maruyama K, Itakura H, Ezaki O (1996) High-fat diet-induced hyperglycemia and obesity in mice: differential effects of dietary oils. Metabolism 45:1539-1546

9. Ruzickova J, Rossmeisl M, Prazak T et al (2004) Omega-3 PUFA of marine origin limit diet-induced obesity in mice by reducing cellularity of adipose tissue. Lipids 39:1177-1185

10. Flachs P, Horakova O, Brauner P et al (2005) Polyunsaturated fatty acids of marine origin upregulate mitochondrial biogenesis and induce beta-oxidation in white fat. Diabetologia 48: 2365-2375

11. Storlien LH, Kraegen EW, Chisholm DJ, Ford GL, Bruce DG, Pascoe WS (1987) Fish oil prevents insulin resistance induced by high-fat feeding in rats. Science 237:885-888

12. Neschen S, Morino K, Dong J et al (2007) $n-3$ fatty acids preserve insulin sensitivity in vivo in a PPAR-alpha-dependent manner. Diabetes 56:1034-1041

13. Sanderson LM, de Groot PJ, Hooiveld GJ et al (2008) Effect of synthetic dietary triglycerides: a novel research paradigm for nutrigenomics. PLoS ONE 3:e1681 
14. Jump DB (2004) Fatty acid regulation of gene transcription. Crit Rev Clin Lab Sci 41:41-78

15. Neschen S, Morino K, Rossbacher JC et al (2006) Fish oil regulates adiponectin secretion by a peroxisome proliferator-activated receptor-dependent mechanism in mice. Diabetes 55:924-928

16. Serhan CN (2005) Novel omega-3-derived local mediators in antiinflammation and resolution. Pharmacol Ther 105:7-21

17. Teran-Garcia M, Adamson AW, Yu G et al (2007) Polyunsaturated fatty acid suppression of fatty acid synthase (FASN): evidence for dietary modulation of NF-Y binding to the Fasn promoter by SREBP-1c. Biochem J 402:591-600

18. Jucker BM, Cline GW, Barucci N, Shulman GI (1999) Differential effects of safflower oil versus fish oil feeding on insulinstimulated glycogen synthesis, glycolysis, and pyruvate dehydrogenase flux in skeletal muscle: a ${ }^{13} \mathrm{C}$ nuclear magnetic resonance study. Diabetes 48:134-140

19. Goldberg RB, Kendall DM, Deeg MA et al (2005) A comparison of lipid and glycemic effects of pioglitazone and rosiglitazone in patients with type 2 diabetes and dyslipidemia. Diabetes Care 28:1547-1554

20. Yang X, Smith U (2007) Adipose tissue distribution and risk of metabolic disease: does thiazolidinedione-induced adipose tissue redistribution provide a clue to the answer? Diabetologia 50: $1127-1139$

21. Nissen SE, Wolski K (2007) Effect of rosiglitazone on the risk of myocardial infarction and death from cardiovascular causes. N Engl J Med 356:2457-2471

22. Lazarenko OP, Rzonca SO, Hogue WR, Swain FL, Suva LJ, Lecka-Czernik B (2007) Rosiglitazone induces decreases in bone mass and strength that are reminiscent of aged bone. Endocrinology 148:2669-2680

23. Kim JK, Fillmore JJ, Gavrilova O et al (2003) Differential effects of rosiglitazone on skeletal muscle and liver insulin resistance in A-ZIP/F-1 fatless mice. Diabetes 52:1311-1318

24. Tsuchida A, Yamauchi T, Takekawa S et al (2005) Peroxisome proliferator-activated receptor (PPAR)alpha activation increases adiponectin receptors and reduces obesity-related inflammation in adipose tissue: comparison of activation of PPARalpha, PPARgamma, and their combination. Diabetes 54:3358-3370

25. Kim H, Haluzik M, Gavrilova O et al (2004) Thiazolidinediones improve insulin sensitivity in adipose tissue and reduce the hyperlipidaemia without affecting the hyperglycaemia in a transgenic model of type 2 diabetes. Diabetologia 47:2215-2225

26. Lebrasseur NK, Kelly M, Tsao TS et al (2006) Thiazolidinediones can rapidly activate AMP-activated protein kinase (AMPK) in mammalian tissues. Am $\mathrm{J}$ Physiol Endocrinol Metab 291(1):E175-E181

27. Wilson-Fritch L, Nicoloro S, Chouinard M et al (2004) Mitochondrial remodeling in adipose tissue associated with obesity and treatment with rosiglitazone. J Clin Invest 114:1281-1289

28. Hevener AL, Olefsky JM, Reichart D et al (2007) Macrophage PPAR gamma is required for normal skeletal muscle and hepatic insulin sensitivity and full antidiabetic effects of thiazolidinediones. J Clin Invest 117:1658-1669

29. Riserus U, Tan GD, Fielding BA et al (2005) Rosiglitazone increases indexes of stearoyl-CoA desaturase activity in humans: link to insulin sensitization and the role of dominant-negative mutation in peroxisome proliferator-activated receptor-gamma. Diabetes 54:1379-1384

30. Todoric J, Loffler M, Huber $\mathrm{J}$ et al (2006) Adipose tissue inflammation induced by high-fat diet in obese diabetic mice is prevented by $n-3$ polyunsaturated fatty acids. Diabetologia 49:2109-2119

31. Flachs P, Mohamed-Ali V, Horakova O et al (2006) Polyunsaturated fatty acids of marine origin induce adiponectin in mice fed high-fat diet. Diabetologia 49:394-397
32. Rossmeisl M, Jelenik T, Jilkova $Z$ et al (2009) Prevention and reversal of obesity and glucose intolerance in mice by DHAderivatives. Obesity doi:10.1038/oby.2008.602

33. Polak J, Kovacova Z, Jacek M et al (2007) An increase in plasma adiponectin multimeric complexes follows hypocaloric dietinduced weight loss in obese and overweight pre-menopausal women. Clin Sci (Lond) 112:557-565

34. Baranowski M, Zabielski P, Blachnio A, Gorski J (2008) Effect of exercise duration on ceramide metabolism in the rat heart. Acta Physiol (Oxf) 192:519-529

35. Pravenec M, Kazdova L, Landa V et al (2003) Transgenic and recombinant resistin impair skeletal muscle glucose metabolism in the spontaneously hypertensive rat. J Biol Chem 278:45209-45215

36. Rossmeisl M, Kovar J, Syrovy I et al (2005) Triglyceridelowering effect of respiratory uncoupling in white adipose tissue. Obes Res 13:835-844

37. Haemmerle G, Zimmermann R, Hayn M et al (2002) Hormonesensitive lipase deficiency in mice causes diglyceride accumulation in adipose tissue, muscle, and testis. J Biol Chem 277:4806-4815

38. Cinti S, Mitchell G, Barbatelli G et al (2005) Adipocyte death defines macrophage localization and function in adipose tissue of obese mice and humans. J Lipid Res 46:2347-2355

39. Burcelin R, Crivelli V, Dacosta A, Roy-Tirelli A, Thorens B (2002) Heterogeneous metabolic adaptation of C57BL/6J mice to high-fat diet. Am J Physiol Endocrinol Metab 282:E834-E842

40. Park SY, Kim HJ, Wang S et al (2005) Hormone-sensitive lipase knockout mice have increased hepatic insulin sensitivity and are protected from short-term diet-induced insulin resistance in skeletal muscle and heart. Am J Physiol Endocrinol Metab 289: E30-E39

41. Rossetti L, Giaccari A (1990) Relative contribution of glycogen synthesis and glycolysis to insulin-mediated glucose uptake. A dose-response euglycemic clamp study in normal and diabetic rats. J Clin Invest 85:1785-1792

42. Bonen A, Clark MG, Henriksen EJ (1994) Experimental approaches in muscle metabolism: hindlimb perfusion and isolated muscle incubations. Am J Physiol 266:E1-E16

43. Okuno A, Tamemoto H, Tobe K et al (1998) Troglitazone increases the number of small adipocytes without the change of white adipose tissue mass in obese Zucker rats. J Clin Invest 101:1354-1361

44. Gahceci M, Gokalp D, Bahceci S, Tuzcu A, Atmaca S, Arikan S (2007) The correlation between adiposity and adiponectin, tumor necrosis factor alpha, interleukin-6 and high sensitivity C-reactive protein levels. Is adipocyte size associated with inflammation in adults? J Endocrinol Invest 30:210-214

45. Pajvani UB, Hawkins M, Combs TP et al (2004) Complex distribution, not absolute amount of adiponectin, correlates with thiazolidinedione-mediated improvement in insulin sensitivity. J Biol Chem 279:12152-12162

46. Baker PW, Gibbons GF (2000) Effect of dietary fish oil on the sensitivity of hepatic lipid metabolism to regulation by insulin. J Lipid Res 41:719-726

47. Laplante M, Festuccia WT, Soucy G et al (2009) Tissue-specific postprandial clearance is the major determinant of PPAR-gammainduced triglyceride lowering in the rat. Am J Physiol Regul Integr Comp Physiol 296:R57-R66

48. Ton MN, Chang C, Carpentier YA, Deckelbaum RJ (2005) In vivo and in vitro properties of an intravenous lipid emulsion containing only medium chain and fish oil triglycerides. Clin Nutr 24:492-501

49. Suchankova G, Tekle M, Saha AK, Ruderman NB, Clarke SD, Gettys TW (2005) Dietary polyunsaturated fatty acids enhance hepatic AMP-activated protein kinase activity in rats. Biochem Biophys Res Commun 326:851-858

50. Gibbons GF, Wiggins D, Brown AM, Hebbachi AM (2004) Synthesis and function of hepatic very-low-density lipoprotein. Biochem Soc Trans 32:59-64 